\title{
Premio "Ecosistemas" al mejor resumen de Tesis Doctoral publicado en 2015
}

\author{
J.A. Blanco ${ }^{1, *}$, J.A. Hódar², Ana L. Llandres ${ }^{3}$ \\ (1) Universidad Pública de Navarra, Pamplona, Navarra, 31006, España. \\ (2) Universidad de Granada, Granada, 18071, España. \\ (3) IRBI, Université François-Rabelais, Tours, 37200, Francia.
}

*Autor de correspondencia: J.A. Blanco [juan.blanco@unavarra.es]

Blanco, J.A., Hódar, J.A., Llandrés, A.L. 2016. Premio "Ecosistemas" al mejor resumen de Tesis Doctoral publicado en 2016. Ecosistemas 25(1): 72. Doi.: 10.7818/ECOS.2016.25-1.9

En el año 2015 se publicaron en Ecosistemas cuatro resúmenes de Tesis. Siguiendo las normas del premio, por cada tramo de ocho resúmenes de Tesis publicados la revista otorga un premio (Cayuela et al. 2013), por lo que este año se galardona a uno de los autores. Al igual que otros años, el comité evaluador está constituido por un miembro del comité editorial de la revista, un miembro de la Junta de la Asociación Española de Ecología Terrestre (AEET) y un evaluador externo. Siguiendo la tónica habitual en los resúmenes enviados a esta revista su calidad y la de las tesis a las que hacen referencia, ha sido muy alta, por lo que no ha sido fácil llegar a un consenso. El premio ha sido concedido al resumen de la Tesis Doctoral titulada "Retos para la conservación de los macroinvertebrados acuáticos y sus hábitats en la península ibérica", elaborada por Simone Guareschi (2015) en el Departamento de Ecología e Hidrología de la Universidad de Murcia bajo la dirección de los Drs. Andrés Millán Sánchez, Josefa Velasco García y Pedro Abellán Ródenas. En virtud del acuerdo alcanzado con la Junta Directiva de la AEET, el autor premiado obtendrá una inscripción gratuita a la AEET durante un año y un diploma acreditativo del Premio.

Desde estas páginas agradecemos las contribuciones de todos aquellos autores que han publicado sus resúmenes de Tesis en Ecosistemas y seguimos animando a todos aquellos investigadores que presenten su Tesis durante este año para que envíen un resumen de la misma a esta revista.

\section{Referencias}

Cayuela, L., Alonso, Á., Escudero, A., Quero, J.L. 2013. Premio "Ecosistemas" al mejor resumen de Tesis Doctoral publicado en esta revista en 2012. Ecosistemas 22(1): 70.

Guareschi, S. 2015. Retos para la conservación de los macroinvertebrados acuáticos y sus hábitats en la península ibérica. Ecosistemas 24(1):115118. 